\title{
Is it possible to foster first-rate publishers through a journal publishing cooperative in Korea?
}

\section{Sun Huh}

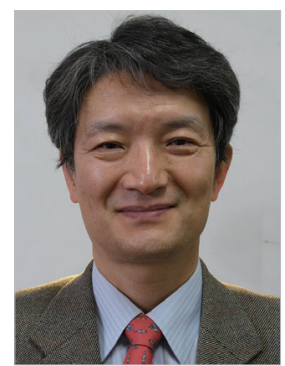

Ethics Editor, Archives of Plastic Surgery

Department of Parasitology and Institute of Medical Education, Hallym University College of Medicine, Chuncheon, Korea

\section{WHY DO LOCAL JOURNALS COOPERATE WITH INTERNATIONAL COMMIERCIAL
PUBLISHIING COMPANIES?}

Most scholarly journals published by academic societies or nonprofit organizations in Korea have been published by the societies or organizations themselves. In particular, medical journals have been published without the help of international commercial publishing companies. However, some journals have begun to collaborate with large companies including Elsevier, SpringerNature, and Taylor-Francis. Furthermore, scholarly journal editors in Korea frequently receive requests from those companies to collaborate in publishing. Some editors have accepted such proposals. The merit of collaborating with those companies is that they can handle the entire publishing process except peer review. The editor and editorial board members can focus solely on manuscript review to improve the quality of journal articles. All other processes, from submission to final publication, are handled by the companies. The difficulties in collaborating with those companies include the higher article processing charge because most society-run journals in Korea have adopted an open-access policy. The second disadvantage is that it is difficult to provide continuity with specific aspects of the journal and its functions, such as the history of editorial members or previous instructions to authors; metrics data including PubMed link-out and cited-by statistics via Crossref; word clouds of journal con- tent; and prompt inclusion of new policies such as principles of transparency and best practice in scholarly publishing [1].

\section{PRESENT SITUATION OF PUBLICATION-RELATED COMPANIES AND LIMITATIONS}

Currently, Korean editors collaborate with companies that play specific roles, such as PDF production and printing; information technology, including XML production, homepage maintenance, and the e-submission system; manuscript editing; English proofreading; and illustrations of figures and diagrams. Those companies in Korea are excellent, making it possible for society journals to maintain top-level editing and production. However, those companies currently have limitations with regard to the following roles: (1) Applications to local and international indexing databases: the Korea Citation Index, Directory of Open Access Journals, Agricola, Engineering Index, PsycINFO, Chemical Abstract Services, BIOSIS Preview, CINAHL, EBSCO, ERIC, Westlaw, EconLit, Food Science and Technology Abstracts, Zoological Record, MEDLINE, PubMed Central, Scopus, EMBASE, SCIE, ESCI, SSCI, and A\&HCI; (2) Improvement of journal policies: editorial policy, research and publication ethics, instructions to authors, principles of transparency and best practice in scholarly publishing, and advertisement policies; (3) Legal issues and practice: copyright, license, allowance of commercial use of articles, disclaimers, the 
process of dealing with complaints from readers or submitters, and archiving; or (4) Research and development: presentation at editors' meetings, the development of new policies or tools for the journal, surveys on journal development, and bibliometric analysis.

\section{HOW CAN SOCIETY EDITORS OVERCOME THOSE WEAKNESSES?}

A possible idea for overcoming those weaknesses is to organize a scholarly journal publishing cooperative, in which editors became members of a non-profit cooperative. They can then recruit first-rate publication-related companies in Korea to work together for journal publishing. Those companies are incentivized to participate in the cooperative since customers (editors) became partners, enabling them to work continuously without the need for ongoing marketing. Members of the cooperative pay the costs to maintain the cooperative and to train managing editors who can carry out the roles listed above. Individual editors can work with appropriate companies for their journals as before.

The background of this idea originates from a situation in 2018 in which a PubMed Central (PMC) journal from Korea was dropped from PMC due to issues involving research and publication ethics. In this journal, photo of bodies and eyemasked faces were presented in three case reports without informed consent. Meanwhile, another journal that received a warning regarding the same ethical issue from PMC responded appropriately by publishing corrigenda that stated that informed consent statements had been received, but their inclusion was omitted during the editorial process; furthermore, the permission number from the Animal Ethics Committee for an animal experiment was re-described in the corrigenda [2]. An editorial on how to deal with ethical issues involving animal experiments and identifiable photographs was published [3]. After that, the ethical issues flagged by PMC were resolved so that the journal could remain in PMC. In light of these two cases, I decided to propose this cooperative as a way to support editors. I consult with editors more than 70 times a year, and the content of these consultations is nearly the same for all editors. It may be more efficient to help editors by organizing a cooperative and training professional managing editors who can help editors with a variety of issues in journal editing and publishing.

\section{CASES OF JOURNAL PUBLISHING COOPERATIVES IN THE WORLD}

An "Open Access Publishing Cooperative Study" was conduct- ed with support from the Public Knowledge Project [4]. This study presented an open-access publishing model that could transform the extant subscription-based model to an open-access model. The problem is the budget; therefore, it was suggested that libraries and public funds should provide the needed budgetary resources. With an appropriate budget, publishers can transform their journals into open-access journals with a reasonable article processing charge. However, my suggestion is different from that model. Most society journals in Korea are already open-access, with revenues from society funds, article processing charges, the Korean government's support, and advertisements. In the field of book publishing, a cooperative was developed that comprised an intermediate stage between traditional publishing and self-publishing [5]. However, I was not able to find a model of a scholarly journal publishing cooperative that precisely corresponded to my idea.

\section{OPINIONS OF COLLEAGUE EDITORS ON A PUBLISHING COOPERATIVE}

In December 8, 2018, I invited nine colleague editors for a mutual discussion about the launch of a publishing cooperative. The following opinions were expressed:

The intention is very good; however, there should be a clearer benefit of participating in the cooperative. Currently, all publishing processes are initiated by the society. What are the distinctive responsibilities of the cooperative?

We should catch up with technological innovations, such as interactive PDFs made by journal article tag suite (JATS)-toPDF conversion. The role of the managing editor is important for adding journals to a variety of indexing databases. Tailored services for each journal are required. It would be best if all other publishing processes, including those mentioned above, would be done by the cooperative, enabling editors to focus on peer review.

I would be worried about the cooperative becoming a new governing body of the journals. Therefore, reasonable rules would be needed to eliminate the possibility of an individual engaging in dogmatic, top-down management processes.

The concept of the cooperative is difficult to understand. The governing body is a major question to be resolved. Another choice could be for societies to participate as clients instead of as cooperative members. The cooperative is recommended to play the role of a Copyright Clearance Center.

Through this cooperative, societies can maintain large-scale, first-rate publishing. Each society can receive benefits from this cooperative through a journal supporting system. 
It would be good to create a network of journals through the cooperative. Sharing of reviewers may be also possible.

We have been slow to adopt recent innovations in scholarly journal publishing because editorship is a voluntary job. The cooperative may be able to hire editors with professional knowledge and skills. Societies may pay an extra fee for the cooperative to hire a managing editor.

In scholarly journal publishing, novel developments in professional content and technology are continually introduced; therefore, there should be a professional full-time managing editor who can adopt these innovations and resolve resultant publishing-related issues. The degree to which these issues can be solved by editors who work voluntarily is limited.

Support from a professional editor is required in the submission process. The number of submissions from outside Korea is increasing year by year, meaning that the role of a professional managing editor should be introduced in journal publishing. A cooperative can provide support for the functions that are difficult for present companies to provide.

To catch up with international trends in scholarly journal publishing, Korean editors should be able to attend international meetings. This can be difficult for editors of specific societies due to budgetary and time constraints, but doing so will be more possible if we train full-time managing editor through the cooperative.

\section{PREPARATIONS FOR THE FUTURE}

The concept of a publishing cooperative is still unfamiliar to editors. However, we should overcome the deficiencies of the present society journal publishing system to compete with international commercial publishing companies, which have an enormous impact on scholarly journal publishing. Over the 13 years from 1997 to 2009, six publishing companies (Elsevier, Springer, John Wiley, Taylor \& Francis, Blackwell, and Kluwer) published $50 \%$ of the journals listed in Web of Science. Eight publishing companies (Elsevier, John Wiley, Springer, American Chemical Society, Blackwell, Lippincott Williams \& Wilkins, Taylor \& Francis, and the American Institute of Physics) published $50 \%$ of the articles [6]. There is still no internationallybranded journal publishing company in Asia. All digital publishing standards and innovations have been driven by those large companies, including digital object identifiers, Crossmark, FundRef, and text and data mining [7]. We, as Korean and Asian editors, have worked diligently to catch up with those new standards. Korean journals - and especially Korean medical journals-have advanced to the international level rapidly after adopting digital standards $[8,9]$ and innovative platforms [10] including JATS XML [11] and an open-data policy [12-14]. Nonetheless, it remains uncertain whether such a cooperative in Korea can be established and function at an international level. When we establish this cooperative, it may be possible for us to participate in a discussion about new standards of journal publishing.

\section{NOTES}

\section{Conflict of interest}

No potential conflict of interest relevant to this article was reported.

\section{ORCID}

Sun Huh https://orcid.org/0000-0002-8559-8640

\section{REFERENCES}

1. Huh S. Adherence of the annals of pediatric endocrinology \& metabolism to the principles of transparency and best practice in scholarly publishing. Ann Pediatr Endocrinol Metab 2018;23:1-3.

2. Editorial office, Archives of Plastic Surgery. Corrigenda: omission of the description of informed consent on the identifiable photos and the description on ethical treatment of experimental animals. Arch Plast Surg 2017;44:575-6.

3. Huh S. How to deal with ethical issues involving animal experiments and identifiable photographs in articles published in Archives of Plastic Surgery. Arch Plast Surg 2017;44:4756.

4. Naim K, Stranack K, Willinsky J. Open access publishing cooperative study: final report [Internet]. Public Knowledge Project; c2017 [cited 2018 Dec 25]. Available from https:// docs.google.com/document/d/1COaY7PM8jXA97b9uM pSQ0a0vYhQGSaDrIooGvd8G2Jw/edit\#.

5. Bastian D. The advantages and disadvantages of cooperative publishing [Internet]. Toronto, ON: BPS Books [cited 2018 Dec 25]. Available from http://www.bpsbooks.com/BPSBooks-blog/bid/19640/The-Advantages-and-Disadvantagesof-Cooperative-Publishing.

6. Didegah F, Gazni A. The extent of concentration in journal publishing. Learn Publ 2011;24:303-10.

7. Lammey R. How to apply CrossMark and FundRef via CrossRef extensible markup language. Sci Ed 2014;1:84-90.

8. Jeong GH, Huh S. Status of digital standards in Korean medical journals in 2016. Sci Ed 2016;3:100-4.

9. Huh S. Recent advances of medical journals in Korea and and further development strategies: is it possible for them to 
publish Nobel Prize-winning research? J Korean Med Assoc 2018;61:524-31.

10. Kim S, Chung E, Lee JY. Latest trends in innovative global scholarly journal publication and distribution platforms. Sci Ed 2018;5:100-12.

11. Schwarzman AB. Journal Article Tag Suite subset and Schematron: achieving the right balance. Sci Ed 2018;5:2-15.

12. Huh S. Promotion to MEDLINE, indexing with Medical Subject Headings, and open data policy for the Journal of Educational Evaluation for Health Professions. J Educ Eval Health Prof 2016;13:14.

13. Kim K. Open data policy of Science Editing. Sci Ed 2018;5: 91.
14. Huh S. Updates from 2018: being indexed in EMBASE, becoming an affiliated journal of the World Federation for Medical Education, implementing an optional open data policy, adopting principles of transparency and best practice in scholarly publishing, and appreciation to reviewers. J Educ Eval Health Prof 2018;15:36.
Correspondence: Sun Huh

Department of Parasitology and Institute of Medical Education, Hallym University College of Medicine, 1 Hallimdaehak-gil, Chuncheon 24252, Korea

Tel: +82-33-248-2652, Fax: +82-33-241-6765, E-mail: shuh@hallym.ac.kr

Received: 25 Dec 2018 • Revised: 25 Dec 2018 • Accepted: 25 Dec 2018

pISSN: 2234-6163 • elSSN: 2234-6171

https://doi.org/10.5999/aps.2019.01543• Arch Plast Surg 2019;46:3-6 